\title{
A RELAÇÃO ENTRE O LETRAMENTO MULTIMODAL E OS MULTILETRAMENTOS NA LITERATURA CONTEMPORÂNEA: ALINHAMENTOS E DISTANCIAMENTOS
}

\author{
LA RELACIÓN ENTRE LA LITERACÍA MULTIMODAL Y LAS MULTILITERACÍAS EN LA LITERATURA \\ CONTEMPORANEA: ALINEAMIENTOS Y DISTANCIAMIENTOS
}

THE CONCEPT OF MULTIMODAL LITERACY AND ITS ROLE IN THE MULTILITERACIES APPROACH

\author{
Nathalia Rodrigues Catto* \\ Universidade Federal de Santa Maria - UFSM \\ Instituto Federal Farroupilha
}

\begin{abstract}
RESUMO: No presente trabalho, proponho uma discussão sobre o conceito de letramento multimodal e o seu papel na abordagem dos multiletramentos. Dois objetivos guiam essa discussão: primeiro, identificar como a literatura conceitua os multiletramentos e o letramento multimodal em busca de definições, características, saberes envolvidos e encaminhamentos pedagógicos em cada uma, e, em segundo lugar, verificar o papel do letramento multimodal nos multiletramentos. Em última instância, este levantamento propõe um debate entre pesquisas sobre o assunto na tentativa de conceituar o letramento multimodal e esclarecer de que maneira cada um desses trabalhos se alinham ou se distanciam em suas discussões.

PALAVRAS-CHAVE: análise conceitual; letramento multimodal; multiletramentos; multimodalidade.
\end{abstract}

RESUMEN: En el presente trabajo, propongo una discusión sobre el concepto de literacía multimodal y su papel en el abordaje de las multiliteracías. Dos objetivos guían esa discusión: primero, identificar cómo la literatura conceptúa las multiliteracías y la literacía multimodal en búsqueda de definiciones, características, saberes involucrados y encaminamientos pedagógicos en cada una, y, en segundo lugar, verificar el papel de la literacía multimodal en las multiliteracías. En última instancia, este levantamiento propone un debate entre investigaciones sobre el asunto en un intento de conceptuar la literacía multimodal y aclarar de qué manera cada uno de esos trabajos se acerca o se distancia en sus discusiones.

PALABRAS-CLAVE: análisis conceptual; literacía multimodal; multiliteracías.

ABSTRACT: In the present study, a discussion is proposed regarding the concept of multimodal literacy and its role in the multiliteracies approach. The objective of the research is twofold: first, to identify how the current literature conceptualizes multiliteracies and multimodal literacy, concerning definitions, characteristics, knowledge involved and pedagogical frameworks in each one; and, secondly, to verify the role of the multimodal literacy in relation to the multiliteracies. Furthermore, this analysis offers a debate on researches about the topic which aims at defining multimodal literacy and clarifying to what extent each of these studies are consensual or divergent in their discussions.

KEYWORDS: conceptual analysis; multimodal literacy; multiliteracies; multimodality.

\section{INTRODUÇÃO}

Estudos recentes sobre letramento (THE NEW LONDON GROUP, 1996; COPE; KALANTZIS, 2000, 2008; KRESS, 2003; DIONÍSIO, 2005) têm apontado que a participação bem sucedida nas práticas sociais contemporâneas, marcadas pela diversidade cultural, linguística e tecnológica, exige múltiplos conhecimentos, habilidades e procedimentos. No contexto escolar, tal demanda convoca pedagogias que deem conta dessa diversidade, como a pedagogia dos multiletramentos, proposta pelo Grupo de Nova Londres (1996; COPE; KALANTZIS, 2000). Essa proposta pedagógica oferece uma alternativa de ensino que permite inserir os alunos em contextos culturais variados por meio do desenvolvimento de saberes de produção e consumo de textos em vista de uma participação como agente (COPE; KALANTZIS, 2000). Para que tal proposta seja recontextualizada para o contexto de ensino, é necessário compreender o que essa perspectiva demanda, sobretudo, definir os aspectos que fundamentam a abordagem dos multiletramentos.

O modelo dos multiletramentos destaca dois argumentos importantes e correlacionados na reavaliação sobre os letramentos (no plural), múltiplos em dois sentidos: 1) na diversidade cultural e linguística; e 2) na 
influência de novas tecnologias comunicativas (COPE; KALANTZIS, 2008, p. 197). O primeiro inclui as múltiplas variedades linguísticas e culturais presentes nos âmbitos profissional, político, escolar, e o segundo contempla a multimodalidade como inerente às formas contemporâneas de produção de sentido e os novos espaços por meio dos quais interagimos. É com base no segundo argumento que a discussão do presente trabalho se desdobra ${ }^{1}$ na questão: quais saberes, processos e habilidades fazem parte do letramento multimodal?

Portanto, o objetivo do presente trabalho é examinar a função do letramento multimodal na abordagem dos multiletramentos em vista da relevância de tal conceito dentro dessa abordagem. Apresento uma discussão na tentativa de oferecer um maior detalhamento sobre os conceitos de multiletramentos e, especialmente, de letramento multimodal, apontando suas definições no cenário contemporâneo. Este estudo busca resposta para os seguintes questionamentos: a) Que saberes fazem parte do letramento multimodal?; e b) Qual é o seu papel na proposta de multiletramentos de acordo com a literatura?

\section{METODOLOGIA}

Foram selecionados trabalhos publicados a partir de 1996, data da primeira publicação sobre multiletramentos pelo Grupo de Nova Londres (1996), em periódicos da área de Linguística Aplicada, no Google Acadêmico e em livros sobre o tema ${ }^{2}$. O corpus foi composto por meio da coleta de trabalhos cujo título contivesse os termos "multiletramentos", "multiliteracies", "letramento multimodal", "multimodal literacy" e/ou os termos "multimodalidade + letramento". Em segundo lugar, foi verificada a relevância da discussão apresentada em cada trabalho conforme os objetivos do presente estudo a partir da leitura do resumo e/ou da primeira seção de cada trabalho.

Com base nos trabalhos coletados, os procedimentos metodológicos envolveram basicamente duas etapas. Em primeiro lugar, foi realizada uma identificação sobre como cada uma das propostas é conceituada, buscando: definições, objetivos, características, saberes envolvidos e encaminhamentos pedagógicos. A partir dessa identificação, foram analisados esses elementos nos trabalhos do corpus a fim de verificar como situavam o letramento multimodal em relação aos multiletramentos. Proponho, então, uma discussão sobre os trabalhos selecionados na tentativa de estabelecer correlações entre os mesmos, organizando o debate em torno de alinhamentos e distanciamentos conceituais. É importante salientar que discutir em profundidade a proposta pedagógica em cada uma das abordagens é tarefa para um próximo estudo.

\section{MULTILETRAMENTOS}

A necessidade de expandir a visão de letramento tradicional, focado predominantemente nas habilidades de leitura e escrita da linguagem verbal (JEWITT, 2008, p. 244), para uma proposta mais abrangente sobre a linguagem, como gênero discursivo, considerando os variados recursos semióticos mobilizados, é consensual entre muitos pesquisadores. Tal expansão estaria relacionada ao contexto contemporâneo marcado, principalmente, por grandes desenvolvimentos tecnológicos e pelo fenômeno da globalização, o qual tem como uma de suas consequências a aproximação entre a imensa diversidade cultural e social.

Nesse contexto, apesar da relevância do letramento voltado para o exame da linguagem verbal, surge a necessidade de pensar novas formas de letramento. Uma das discussões iniciais sobre a expansão do conceito de letramento proposta pelo Grupo de Nova Londres (1996) apontou o termo "multiletramentos" para definir uma nova abordagem, a qual oferece argumentos para repensar os letramentos e suas implicações para a participação social na vida pública, econômica e comunitária (THE NEW LONDON GROUP, 1996).

\footnotetext{
${ }^{1}$ Apesar da importância do primeiro argumento, no entanto, o espaço e tempo limitados e os objetivos do presente trabalho impedem uma discussão detalhada sobre tal aspecto. Sugiro uma análise aprofundada de ambos os pontos em trabalhos futuros.

${ }^{2}$ Reconheço a limitação do presente estudo visto que os livros foram selecionados também a partir do critério disponibilidade de acesso e muitos, cujo título indicava grande relevância ao propósito do presente trabalho, não estavam ao meu alcance.
} 
Várias atividades das quais participamos exigem o conhecimento sobre inúmeros saberes contemplados nos multiletramentos, baseados na manipulação de uma multiplicidade de linguagens, culturas, práticas sociais e contextos, diferentemente de uma visão de letramento embasada na apreensão de regras e sua aplicação de maneira correta (COPE; KALANTZIS, 2008). À medida que nos educamos em direção aos multiletramentos, as ações em busca de uma participação mais influente na vida contemporânea se tornam mais informadas segundo conhecimentos e processos especializados. Tal especialização está relacionada a saber interagir em situações (gêneros discursivos) familiares e não familiares e ser capaz de procurar por pistas para uma participação mais apropriada nessas práticas (COPE; KALANTZIS, 2008), uma vez que os saberes dos multiletramentos podem ser definidos como "as habilidades de interagir com a pluralidade (LO BIANCO, 2000, p. 99), como leitores e produtores de texto." (MOTTA-ROTH; HENDGES, 2010, p. 45).

A noção de design ${ }^{3}$ é de grande importância na perspectiva dos multiletramentos. Essa noção orienta uma nova visão sobre letramento e pode ser entendida como um processo dinâmico, o qual compreende tanto a produção de sentido quanto o resultado dessa produção. Uma concepção dessa natureza pode ser explicada, de acordo com Cope e Kalantzis (2008), essencialmente sob dois prismas: o da variação linguística diferentes sotaques, registros e dialetos - e o de agência e subjetividade. Ou seja, "a realidade da língua não depende simplesmente da reprodução de padrões e convenções regularizados", uma vez que cada ato de linguagem depende da seleção de recursos semióticos específicos que servem aos propósitos dos participantes naquele momento (COPE; KALANTZIS, 2008, p. 204).

Apesar dessa ampliação na noção sobre a linguagem, a proposta dos multiletramentos reconhece o papel do letramento tradicional e enfatiza a complementaridade entre formas mais tradicionais de letramento, as quais envolvem leitura e escrita da linguagem verbal, como processos socialmente constituídos, em interação com novas formas de negociação de significado, baseadas na manipulação de diferentes recursos semióticos, como imagens e sons.

Uma vez que o objetivo pedagógico dos multiletramentos é "proporcionar aos alunos uma percepção sobre como padrões de significação são produtos de diferentes contextos" (COPE, KALANTZIS, 2008, p. 205), o reconhecimento e uso desses padrões depende, dentre outros fatores, da manipulação de diferentes modos semióticos. O letramento multimodal é uma das propostas da pedagogia dos multiletramentos, e está relacionado à referida manipulação de diferentes modos semióticos. Passo, então, na próxima seção, a uma discussão sobre esse conceito e apresento suas principais características.

\section{LETRAMENTO MULTIMODAL}

Conforme indicado no manifesto de 1996 do Grupo de Nova Londres, uma das ideias principais que informa a noção de multiletramentos é a crescente complexidade e inter-relação de diferentes modos semióticos. Dentre as grandes áreas que contemplam essa complexidade e inter-relação, o letramento multimodal recebe atenção especial por incorporar e reunir os saberes necessários para lidar com esses diversos modos semióticos (THE NEW LONDON GROUP, 1996, p. 17). Considerando os dois argumentos que justificam a multiplicidade defendida pelos multiletramentos, a diversidade cultural e linguística de um lado, e a influência de novas tecnologias comunicativas de outro, “ $[\mathrm{e}] \mathrm{m}$ ambos os casos, tem-se em mente modos de representação mais amplos e mais dinâmicos do que exclusivamente a linguagem verbal” (MOTTA-ROTH; HENDGES, 2010, p. 45). Tais constatações apontam para a importância do letramento multimodal, como um conjunto de práticas que consideram essa ampliação de foco da linguagem verbal para outros modos semióticos a fim de dar conta dessa multiplicidade. Apresento, no Quadro 1 a seguir, os saberes do letramento multimodal descritos na literatura do corpus.

Dentre os saberes do letramento multimodal apontados, um deles revela a essência desse processo: compreender e produzir significados por meio da combinação e do arranjo de diferentes modos semióticos. Para tanto, é necessário conhecimento, em primeiro lugar, sobre as potencialidades de cada um desses modos e, em segundo lugar, sobre a maneira como as combinações criam significado. Em relação ao primeiro aspecto, reconhecer as afordabilidades ${ }^{4}$ de cada modo semiótico é essencial para usá-lo da maneira

\footnotetext{
${ }^{3} \mathrm{O}$ termo design não foi traduzido pelas divergências observadas em relação à tradução de tal termo para o português: alguns trabalhos apontam design como "desenho", outros como "projeto".

4. Afordabilidade é um que proponho na tentativa de oferecer uma tradução para o termo original “affordances”, proposto por Kress e Jewitt (2003).
} 
mais adequada a fim de alcançar os propósitos definidos em cada prática social. Saber, por exemplo, que as imagens se organizam pelo princípio espacial enquanto o texto verbal escrito, pelo princípio temporal (KRESS, 2003) orienta as escolhas mais adequadas em vista do contexto de leitura e/ou produção textual.

Em relação ao segundo aspecto, propostas como as de Martinec e Salway (2005) e Royce (2007) exploram as relações que se estabelecem por meio da combinação de modos semióticos variados, principalmente a relação entre imagem e texto verbal. Tais estudos propõem categorias que definem o tipo de relação estabelecida entre a linguagem verbal escrita e a linguagem não-verbal imagética: complementaridade, sobreposição ou expansão. Essa interação entre linguagem verbal e não verbal é a característica principal da multimodalidade.

Quadro 1 - Síntese dos saberes envolvidos no letramento multimodal descritos em literatura prévia

\begin{tabular}{|l|}
\hline \multicolumn{1}{|c|}{ Conhecimentos do letramento multimodal } \\
\hline - Combinar de maneira informada e qualificada os múltiplos recursos semióticos que \\
medeiam as práticas sociais; \\
- Produzir sentido por meio do arranjo dos recursos semióticos de acordo com o que é \\
considerado central em uma situação particular; \\
- Desenvolver práticas tanto de produção quanto de análise crítica da diversidade de modos \\
semióticos e da interação entre eles.
\end{tabular}

Segundo Cope e Kalantzis (2000, p. 29), de certa forma, toda construção de significado pode ser considerada multimodal. Nesse sentido, na tentativa de responder a essas configurações semióticas complexas, o letramento multimodal (KRESS, 2003; KRESS; JEWITT, 2005; WALSH, 2009) se sustenta por noções centrais como multimodalidade e modo semiótico, e pelas categorias descritivas e analíticas da Gramática do Design Visual (KRESS; van LEEUWEN, 1996, 2001).

A noção de multimodalidade parte da premissa básica de que todos os significados são criados, distribuídos, recebidos e interpretados por meio da combinação de diferentes modos semióticos, estes entendidos como recursos culturalmente disponíveis para criação de sentido, ou ainda, tecnologias para representação de significados (KRESS; JEWITT, 2003). Além da Gramática Sistêmico-Funcional (HALLIDAY, 1994; HALLIDAY, MATTHIESSEN, 2004) cujo foco descritivo e analítico é a linguagem verbal, para compreender o funcionamento da linguagem não verbal imagética, a Gramática Visual constitui-se como uma ferramenta, também descritiva e analítica, a qual tem em sua origem princípios da Linguística Sistêmico-Funcional. Essa gramática oferece uma metalinguagem para descrever de maneira sistemática como elementos visuais são usados na construção de significado (KRESS; van LEEUWEN, 1996).

Outro conceito fundamental nessa discussão é o de especialização funcional ${ }^{5}$ (BEZEMER; KRESS, 2008; KRESS, 1997). Esse conceito corresponde ao conhecimento sobre prever/antecipar que recursos semióticos servem melhor aos propósitos comunicativos que configuram determinada ação social reconhecendo os padrões sociais que subjazem à habilidade de agir de forma flexível em contextos variados e adaptar-se a estes (THE NEW LONDON GROUP, 1996, p. 21).

Toda essa reconfiguração social em termos de produção de sentido revela uma noção ampliada de texto, ou seja, "qualquer instância comunicativa em qualquer modo semiótico ou em qualquer combinação de modos" (KRESS, 2003, p. 48), em oposição à visão de texto configurado apenas por meio da linguagem verbal escrita. Além de uma noção ampliada de texto, o letramento multimodal se apoia em algumas premissas, para as quais, saberes correspondentes podem ser definidos. As principais premissas, de acordo com Kress e Jewitt (2003), são o desafio à visão de linguagem verbal como essencial ou suficiente em si mesma; as potencialidades específicas de cada modo semiótico para a comunicação e representação; a manifestação de um sentido parcial por cada modo semiótico em relação ao todo; e a combinação entre os modos semióticos como responsável pela total materialização de gêneros discursivos.

Sobre a influência de novas tecnologias comunicativas no consumo e na produção de textos, espaços como blogs, wikis, jogos online, SMS, chats, e mesmo tecnologias clássicas como o livro didático impresso, exigem novas formas de interagir. Dentre elas, um novo vocabulário: “criamos" e "construímos” em vez de escrever

\footnotetext{
${ }^{5}$ Em inglês, functional specialization.
} 
apenas, e "navegamos" e "exploramos" em vez de ler apenas, pois a participação nesse contexto é visto como um processo ativo e interativo (DALEY, 2003, p. 177-178). É evidente que essa nova concepção demanda uma descentralização em torno de práticas sociais tradicionalmente valorizadas no contexto escolar, do âmbito literário, por exemplo, em direção a práticas antes pouco apreciadas nesse contexto, como a produção de vídeos, conforme aponta Rojo (2012). Exemplos dessa natureza são tomados como ponto de partida na sala de aula por estarem voltados às culturas, aos gêneros, às mídias e às linguagens que fazem parte do contexto onde os alunos estão inseridos.

Uma das habilidades para interagir nesses ambientes é manipular conhecimentos sobre o potencial de modos semióticos diversos e compreender que a escolha entre textos impressos ou eletrônicos, construídos com base na combinação de imagens, sons e/ou palavras depende de propósitos e contextos definidos (BULL; ANSTEY, 2007). A forma como esses modos são arranjados depende do que é considerado central em uma situação particular. Nessa perspectiva, são indispensáveis novas práticas, tanto de produção quanto de análise crítica (ROJO, 2012), porque, segundo Dionísio (2005, p. 131)

[a] noção de letramento como habilidade de ler e escrever não abrange todos os diferentes tipos de representação do conhecimento existentes em nossa sociedade. Na atualidade, uma pessoa letrada deve ser [...] capaz de atribuir sentidos a mensagens oriundas de múltiplas fontes de linguagem, bem como ser capaz de produzir mensagens incorporando múltiplas fontes de linguagem.

Contudo, ações dessa natureza exigem certo grau de propriedade na prática e na compreensão de maneira qualificada sobre as formas de representação que têm predominado nas práticas sociais, como, por exemplo, a relação que se estabelece entre imagens e palavras (THE NEW LONDON GROUP, 1996, p. 9). Para tanto, devemos ser capazes de "analisar discursos multimodais/multimídia" e

dar conta do modo como imagens se tornam um recurso comum para a produção de sentido na sociedade tecnológica e do modo como a combinação entre texto verbal e não verbal se torna uma ferramenta poderosa de mediação na constituição de identidades sociais e relações entre elas. (MOTTA-ROTH; NASCIMENTO, 2009, p. 348 apud MOTTA-ROTH; HENDGES, 2010, p. 61).

Os estudos voltados especificamente para o letramento multimodal (KRESS, 2003; KRESS; JEWITT, 2003; WALSH, 2009) o enquadram como um processo de produção de sentido em que "forma e sentido [estão] sempre ligados, em relação a ser apto para" (KRESS; JEWITT, 2003, p. 10). Um aspecto observado em trabalhos que adotam o termo letramento multimodal indica que muitas das discussões nessa área se direcionam a questões de ensino (DIONÍSIO, 2005; JEWITT, 2005, 2008; WALSH, 2009; ROWSELL; WALSH, 2011). Na mesma direção, grande parte das pesquisas do corpus entende que o conceito de multimodalidade seria o ponto de partida para compreender e explicar como os significados são construídos socialmente e o letramento multimodal como o conjunto de saberes envolvidos na realização dessas construções.

Diferentemente da abordagem dos multiletramentos, a qual apresenta uma proposta pedagógica sistemática para o ensino de linguagem, prevendo etapas delimitadas para o trabalho em sala de aula, as propostas pedagógicas de letramento multimodal ainda são esparsas e pouco sistemáticas e estão voltadas para a análise da multimodalidade em diversas práticas sociais. Um exemplo é o trabalho de Unsworth (2001, 2006), o qual defende o desenvolvimento de uma metalinguagem no ensino para facilitar o reconhecimento sobre como os sistemas semióticos são empregados na produção de sentido (UNSWORTH, 2001, p. 282).

Apesar da ampla relevância do letramento multimodal para os multiletramentos como parte integrante de e essencial a este, algumas pesquisas atribuem equivocadamente a multimodalidade como a única característica da abordagem dos multiletramentos. Duncum (2004), por exemplo, entende multiletramento, o qual é por ele referido no singular, como a produção de sentido por meio da interação de diferentes modos semióticos, ou ainda, ao citar Cope e Kalantzis (2000), como as relações multimodais entre diferentes processos de produção de sentido. A concepção de multiletramentos proposta por Duncum (2004) é limitada à interação entre dois ou mais sistemas semióticos.

Unsworth (2001 p. 8), apesar de reconhecer o caráter múltiplo dos multiletramentos ao utilizar o termo no plural, aponta como saber essencial para os multiletramentos o entendimento sobre "como os recursos da linguagem verbal, das imagens e da retórica digital podem ser empregados independente e interativamente 
para construir diferentes tipos de significado ${ }^{6}$." Contudo, conforme apontado anteriormente, propor uma visão que atenda à realidade dos múltiplos letramentos, no domínio do letramento multimodal, é um dos objetivos principais dos multiletramentos (COPE; KALANTZIS, 2000, 2008, 2009; UNSWORTH, 2001; JEWITT, 2005, 2008; ROJO, 2012). Ou seja, ambos os pressupostos que orientam os multiletramentos, a dimensão multimodal instanciada por diferentes modos semióticos e a multiplicidade de culturas e línguas (ROWSELL; WALSH, 2011, p. 55), devem ser igualmente incorporadas às discussões sobre multiletramentos.

Apesar de ainda serem observados alguns desacordos conceituais, considerando as principais características do letramento multimodal discutidas na literatura prévia, o seu papel na abordagem dos multiletramentos pode ser definido como fundamental. Evidências revelaram que o letramento multimodal é considerado um processo imprescindível para o desenvolvimento dos multiletramentos. Dentre as principais evidências está a noção de multimodalidade, a qual oferece embasamento para uma visão múltipla e ampla sobre como produzimos sentido socialmente. Suas contribuições para os multiletramentos são extremamente relevantes na tentativa de repensar o letramento como um processo multimodal.

\section{CONSIDERAÇÕES FINAIS}

Se a pedagogia dos multiletramentos já previa a extrema relevância da multimodalidade para o contexto em que o manifesto de 1996 foi publicado, as transformações no ambiente de comunicação contemporâneo convocam em caráter de urgência o ensino que explore explicitamente o conceito de multimodalidade (COPE; KALANTZIS, 2009). Nesse sentido, incorporar o conceito de letramento multimodal na educação linguística evidencia uma preocupação com a participação dos alunos nas práticas que configuram a sociedade atual. Dessa forma, as propostas de ensino corresponderiam à orientação de documentos oficiais como as Orientações Curriculares Nacionais, ou seja, “[e $] \mathrm{m}$ vez de preparar um aprendiz para o momento presente, o ensino de letramentos heterogêneos e múltiplos visa a prepará-lo para um futuro desconhecido, para agir em situações novas, imprevisíveis, incertas” (BRASIL, 2006, p. 108-109).

Os saberes que envolvem os multiletramentos contemplam habilidades para interagir tanto com a diversidade de culturas e línguas quanto com a diversidade de tecnologias comunicativas. Manipular as diversas tecnologias comunicativas define a proposta central do letramento multimodal, ou seja, conhecer o papel dos recursos semióticos e o uso integrado dos mesmos na construção de sentido. Em vista de tal constatação, a relação entre o letramento multimodal e os multiletramentos pode ser entendida como intrínseca, visto que ambas são simultaneamente convocadas para interagir nessas novas tecnologias comunicativas em busca de uma expansão no repertório de práticas sociais das quais podemos e sabemos participar.

Apesar de pesquisas sobre o letramento multimodal estarem em desenvolvimento e este ser considerado, portanto, um tema emergente na área de Linguística Aplicada, ainda são necessárias muitas pesquisas, mesmo que, segundo Kress e Jewitt (2003), os resultados apontem para novos questionamentos em vez de proclamar certezas insustentáveis.

\section{REFERÊNCIAS}

BEZEMER, J.; KRESS, G. Writing in multimodal texts: a social semiotic account of designs for learning. Written communication, v. 25, n. 2, p. 166-195, 2008.

BRASIL. Orientações curriculares para o ensino médio - Linguagens, Códigos e suas Tecnologias, v. 1. Brasília: Ministério da Educação/Secretaria de Educação Básica, 2006.

BULL, G.; ANSTEY, M. What's so different about multiliteracies? Curriculum Leadership, v. 5, n. $11,2007$.

COPE, B.; KALANTZIS, M. A grammar of multimodality. International Journal of Learning, v. 16, n. 2, p. $361-425,2009$.

\footnotetext{
${ }^{6}$ No original: "how the resources of language, image and digital rhetorics can be deployed independently and interactively to construct different kinds of meaning."
} 


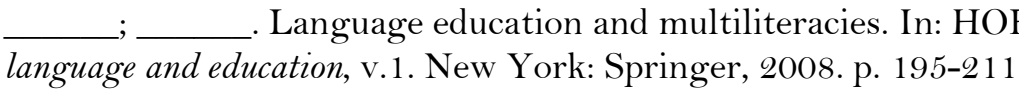

; __ Multiliteracies: the beginnings of an idea. In: COPE, B.; KALANTZIS, M. (Eds.).

Multiliteracies: Literacy learning and the design of social futures. London: Routledge, 2000. p. 3-8.

DALEY, E. Expanding the concept of literacy. Educause revierw, v. 38, n. 2, p. 32-40, 2003.

DIONÍSIO, A. P. Gêneros multimodais e multiletramento. In: KARWOSKI, A. M.; GAYDECZKA, B.; BRITO, K. S. (Orgs.). Gêneros textuais: reflexões e ensino. 2. ed. Rio de Janeiro: Lucerna, 2005. p. 159-177.

DUNCUM, P. Visual culture isn't just visual: multiliteracy, multimodality and meaning. Studies in art education, v. 45, n. 3, p. 252-264, 2004.

HALLIDAY, M. A. K. An introduction to functional grammar. London: Edward Arnold, 1994.

; MATTHIESSEN, C. M. I. M. An introduction to functional grammar. 3. ed. London: Edward Arnold, 2004 .

JEWITT, C. Multimodality and literacy in school classrooms. Review of research in education, v. 32, n. 1, p. 241-267, 2008.

Multimodality, reading and writing. Discourse: studies in the cultural politics of education, v. 26, n. 3, p. 315-331, 2005.

KRESS, G. Literacy in the new media age. New York: Routledge, 2003.

. Before writing: rethinking the paths to literacy. London: Routledge, 1997.

; VAN LEEUWEN, T. Multimodal discourse: the modes and media of contemporary communication.

Great Britain: Hodder Arnold, 2001.

KRESS, G. VAN LEEUWEN. Reading images: the grammar of visual design. London; New York: Routledge, 2006 [1996].

; JEWITT, C. (Orgs.). Multimodal literacy. New York: Peter Lang Publishing, 2003.

LO BIANCO, J. Multiliteracies and multilingualism. In: COPE, B.; KALANTZIS, M. A (Eds.).

Multiliteracies: literacy learning and the design of social futures. Routledge, 2000.

MARTINEC, R.; SALWAY, A. A system for image-text relations in new (and old) media. Visual Communication, v. 4, n. 3, p. 337-371, 2005.

MOTTA-ROTH, D.; HENDGES, G. R. Explorando modalidades retóricas sob a perspectiva da multimodalidade. Letras, v. 20, n. 40, p. 43-66, 2010.

ROJO, R.; MOURA, E. (Orgs.). Multiletramentos na escola. São Paulo: Parábola Editorial, 2012.

ROWSELL, J.; WALSH, M. Rethinking literacy education in new times: multimodality, multiliteracies, and new literacies. Brock education, v. 21, n. 1, p. 53-62, 2011.

ROYCE, T. D. Intersemiotic complementarity: a framework for multimodal discourse analysis. In: ROYCE, T. D.; BOWCHER, W. L. (Orgs.). New directions in the analysis of multimodal discourse. Mahwah, New Jersey: Lawrence Elbaum Associates, 2007. p. 63-109.

THE NEW LONDON GROUP. A pedagogy of multiliteracies: designing social futures. The Harvard educational review, v. 1, n. 66, p. 60-92, 1996.

UNSWORTH, L. Teaching multiliteracies in the English classroom. In: Teaching multiliteracies across the curriculum: changing contexts of text and image in classroom practice. Buckingham: Open University Press, 2001. p. 260-282.

WALSH, M. Pedagogic potentials of multimodal literacy. In: TAN WEE HIN, L.; SUBRAMANIAN, R. (Orgs.). Handbook of research on New Media Literacy at the K-12 level: issues and challenges. Hershey, US: IGI Global, 2009. p. 32-47.

Recebido em 16/04/13. Aprovado em 30/06/13. 